\title{
Natural rubber for sustainable high-power electrical energy generation $\uparrow$
}

Cite this: RSC Adv., 2014, 4, 27905

\author{
Rainer Kaltseis, ${ }^{* a b}$ Christoph Keplinger, ${ }^{\text {abc }}$ Soo Jin Adrian Koh, de \\ Richard Baumgartner, ${ }^{a}$ Yu Feng Goh, ${ }^{e}$ Wee Hoe Ng, ${ }^{e}$ Alexander Kogler, ${ }^{a}$ \\ Andreas Tröls, ${ }^{a}$ Choon Chiang Foo, ${ }^{\text {bd }}$ Zhigang Suo ${ }^{b}$ and Siegfried Bauer ${ }^{a}$
}

\begin{abstract}
Clean, renewable and abundant sources of energy, such as the vast energy of ocean waves, are untapped today, because no technology exists to convert such mechanical motions to electricity economically. Other sources of mechanical energy, such as motions of people and vibrations of buildings and bridges, can potentially power portable electronics and distributed sensors. Here we show that natural rubber can be used to construct generators of high performance and low cost. Natural rubber has higher elastic modulus, fracture energy and dielectric strength than a commonly studied acrylic elastomer. We demonstrate high energy densities $\left(369 \mathrm{~mJ} \mathrm{~g}^{-1}\right.$ ) and high power densities $\left(200 \mathrm{~mW} \mathrm{~g}^{-1}\right)$, and estimate low levelized cost of electricity $\left(5-11 \mathrm{ct} \mathrm{kW}^{-1} \mathrm{~h}^{-1}\right)$. Soft generators based on natural rubber enable clean, low-cost, large-scale generation of electricity.
\end{abstract}

Received 7th April 2014

Accepted 16th June 2014

DOI: $10.1039 / \mathrm{c} 4 \mathrm{ra0} 03090 \mathrm{~g}$

www.rsc.org/advances

can be used to convert mechanical motions to electricity at high

\section{Introduction}

Hydropower and winds have been harvested economically, but most other sources of mechanical energy, such as human motions, ocean waves, and building vibrations, have remained untapped. Harvesting these sources of energy is highly desirable. On a small scale, for example, the power generated from the heels of a walking person may charge mobile devices; a full charge of a smart phone requires about $0.1 \%$ of our daily energy uptake. On a large scale, ocean waves contain sufficient energy to satisfy the total worldwide demand for electrical energy. ${ }^{1}$

No technologies, however, exist to convert these sources of mechanical energy to electricity at low cost. For example, many designs have been proposed to harvest ocean wave energy, ${ }^{2}$ but they are not economically competitive. These devices couple with the ocean waves through large and repeated motions of hard materials. They are costly to construct and maintain in the harsh ocean environment. ${ }^{3}$ Here we show that natural rubber

${ }^{a}$ Department of Soft Matter Physics, Johannes Kepler University, Linz, A-4040, Austria. E-mail: rainer.kaltseis@gmail.com

${ }^{b}$ School of Engineering and Applied Sciences, Harvard University, Cambridge, MA 02138, USA

${ }^{c}$ Kavli Institute for Bionano Science and Technology, Harvard University, Cambridge, Massachusetts 02138, USA

${ }^{d}$ Institute of High Performance Computing, 1 Fusionopolis Way, \#16-16 Connexis, Singapore 138632, Singapore

${ }^{e}$ Department of Mechanical Engineering and Engineering Science Programme, National University of Singapore, 9 Engineering Drive 1, Kent Ridge, Singapore 117576, Singapore

† Electronic supplementary information (ESI) available. See DOI: $10.1039 / \mathrm{c} 4 \mathrm{ra03090g}$ energy and power density, at potentially low cost.

Natural rubber is inexpensive and robust, and has been used in oceans for well over a century as electrical insulators, buoys, etc. ${ }^{4,5}$

A soft generator involves a deformable capacitor operating through electromechanical cycles. ${ }^{6-12}$ A membrane of a soft dielectric is sandwiched between two compliant conductors. The two conductors carry electric charges of the opposite

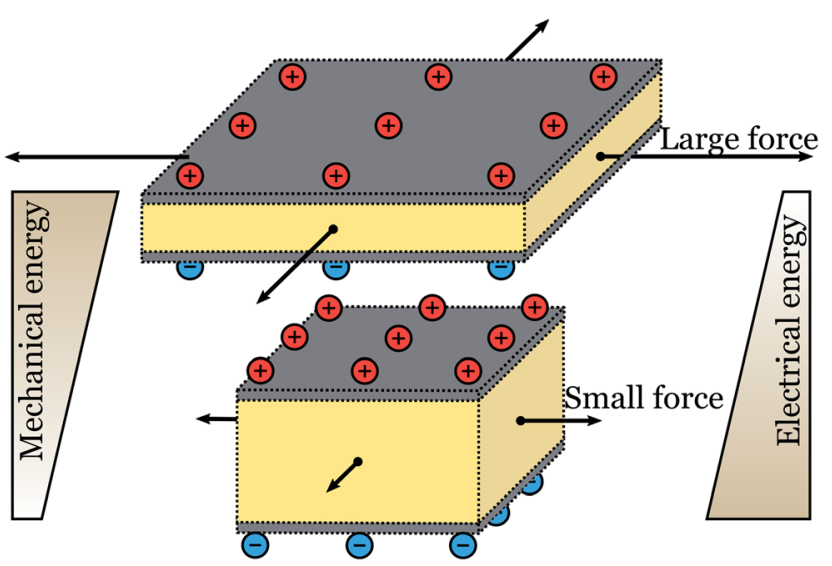

Fig. 1 In a soft generator, mechanical forces do work to raise the voltage of electrical charges. After mechanical forces stretch a rubber membrane (yellow), the compliant electrodes (gray) on opposing faces of the stretched membrane receive charges of opposite polarities from an external source. Subsequently the membrane is disconnected from the external source. When the mechanical forces reduce, the membrane increases thickness and decreases area, raising the fixed amount of charges to a higher voltage. 
polarities (Fig. 1). In one state, a mechanical force stretches the membrane, and the voltage between the two conductors is low. In the other state, when the mechanical force reduces, the membrane decreases the area and increases the thickness, raising the fixed amount of charges to a higher voltage. The change between the two states enables the mechanical force to raise the fixed amount of electrical charges to higher voltage.

Existing demonstrations of soft generators have used acrylic $^{6,8,13-15}$ and silicone-based ${ }^{10,16}$ elastomers. The relatively high cost of these elastomers have prevented them from largescale applications. ${ }^{17-19}$ In addition, the acrylic elastomers are highly viscous; the large energy loss limits the frequency range and conversion efficiency. Furthermore acrylic elastomers have relatively low fracture energy often leading to rupture under electromechanical loads. ${ }^{20}$ We show that natural rubber is much less viscous, and has higher fracture toughness and dielectric strength than the acrylic elastomers. This work asses the aptitude of three materials employed in the same experimental setup, to provide comparative results. We demonstrate the energy conversion capability of natural rubber, and use the results to illustrate the feasibility of deploying natural rubber as a low cost ocean wave energy harvester.

\section{Results}

\section{Material properties}

The basic aptitude of natural rubber for energy harvesting is tested on two example materials based on natural rubber and on commonly used acrylic elastomer. Using commercially available mass products ensures a large material supply chain with identical composition, produced under the quality standards common in industry.

This work characterizes the material properties of three offthe-shelf dielectric elastomers. ZruElast A1040 (ZRU) ${ }^{21}$ is a 300 $\mu \mathrm{m}$ thick natural rubber sheet containing $23 \mathrm{wt} \%$ of inorganic fillers and $1.19 \mathrm{wt} \%$ of carbon. Oppo Band $8003^{\mathrm{TM}}(\mathrm{OP})^{22}$ from Oppo Medical Inc. is a $227 \mu \mathrm{m}$ thick physiotherapy rubber sheet containing $0.96 \mathrm{wt} \%$ inorganic fillers and $0.56 \mathrm{wt} \%$ carbon.

Oppo Band was selected due to the elasticity and mechanical durability that a physiotherapy band is designed for. The acrylic-based material is $1000 \mu \mathrm{m}$ thick VHB4910 from $3 \mathrm{M}^{\mathrm{TM}} .^{23}$

The aptitude of materials for use in soft generators is largely determined by several properties. The dielectric strength $E_{\mathrm{B}}(\lambda)$ and the dielectric permittivity $\varepsilon$ determine the amount of electrical energy $\propto \varepsilon E_{\mathrm{B}}(\lambda)^{2}$ that can be stored. Improving the performance of dielectric materials The elastic stiffness and the limiting stretch determine the amount of mechanical energy that can be stored. The 'mechanical-to-electrical' energy conversion efficiency is limited by dissipative processes such as viscoelastic hysteresis and charge leakage. ${ }^{24}$ The toughness of an elastomer is quantified by fracture energy, namely, the energy needed for a crack to advance per unit area. In order to assess the usefulness of the different elastomers for energy harvesting, we experimentally measure the mechanical and dielectric properties of these materials (Fig. 2 and Table 1). The detailed description of the experimental methods used to determine the material parameters is given in ESI $\dagger$ in the section "Experimental methods".

The dielectric strength is dependent on the state of stretch, and is much larger in natural rubber than in the acrylic elastomer $^{25}$ (Fig. 2a). To obtain the intrinsic dielectric strength of the samples we employ the method of Tröls et al. ${ }^{25}$ preventing any actuation while applying high voltage. Following Koh et al. ${ }^{26}$ we fit our experimental data to the expression

$$
E_{\mathrm{B}}(\lambda)=E_{\mathrm{B}} \lambda^{R}
$$

the unstretched dielectric strength $E_{\mathrm{B}}$ and the strengthening exponent $R$ are material parameters given in Table 1 . We fit the stress-strain relations obtained by a ZWICK universal testing machine under uniaxial tension to the Gent $\operatorname{model}^{27}$ (Fig. 2b). In the Gent model, the parameter $\mu$ is the stiffness and the parameter $J_{\text {lim }}$ determines the maximum squared stretch. The value $J_{\text {lim }}$ of VHB is three times that of OP and ZRU. On the other hand, the stiffness $\mu$ of VHB is one order of magnitude lower than that of natural rubber. Thus VHB is more stretchable than natural rubbers, but less stiff.

Fracture energy indicates the capability of a material to resist the growth of a crack under mechanical load. Fig. 2c shows the nominal stress-stretch relation of samples containing a preexisting crack of $20 \%$ of the materials width under pure-shear deformation. The strain at rupture in precut samples is used to obtain the fracture energy as detailed in the methods section. The fracture energy of natural rubber is almost two times that of VHB at a strain rate of $100 \% / \mathrm{s}$ (Table 1 ). The fracture energy for VHB is consistent with a previously reported result. ${ }^{20}$

All of the tested elastomers exhibit large hysteresis losses in the first loading-unloading cycle, which gradually saturates to a lower value from the $5^{\text {th }}$ cycle onwards. This may be attributed to the Mullins effect, ${ }^{28,29}$ which is most observable in the first few stress cycles of a pristine elastomer, and gradually diminishes for subsequent cycles (details are presented in ESI, Fig. S4 $\dagger$ ). The different filler material of ZRU affects its dielectric strength and causes plastic deformation at large stretches. In the steady state, the energy loss per cycle is larger in the acrylic elastomer than in the natural rubbers (Fig. 2d-f).

With these material properties, we plot regions of allowable states on work-conjugate planes of voltage and charge ${ }^{30}$ for the three materials (Fig. 3). The regions of allowable states are determined by lines of maximum biaxial stretch, dielectric breakdown, and states of zero tensile stress (loss of tension). On this plot, any state located within the shaded regions denotes an allowable state, whereas any state located outside are inaccessible due to the occurrence of one or more modes of failure. The area of the shaded region gives the maximum theoretical specific electrical energy that can be generated ${ }^{26}$ employing biaxial stretch.

The theoretical potential to convert energy of the two rubbers is three times that of acrylic elastomer (Fig. 3). This difference is due to the higher shear modulus and higher dielectric strength of natural rubbers than those of the acrylic elastomer. Direct comparison of OP $\left(3.5 \mathrm{~J} \mathrm{~g}^{-1}\right)$ and $\mathrm{ZRU}\left(3.0 \mathrm{~J} \mathrm{~g}^{-1}\right)$ reveals a 
a)

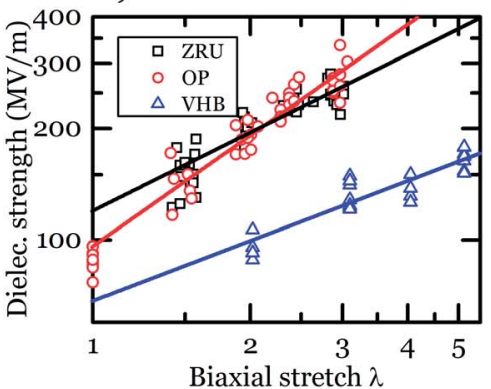

d)

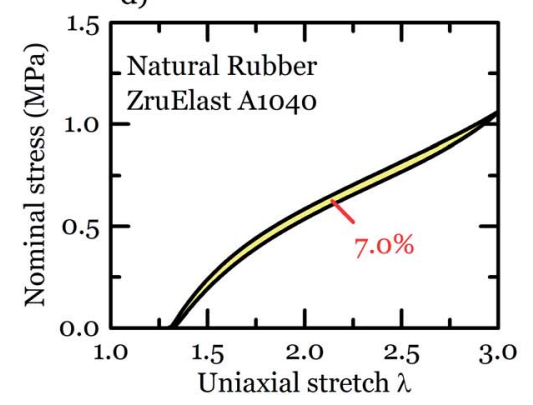

b)

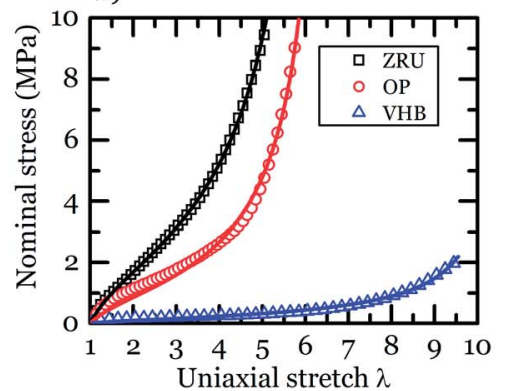

e)

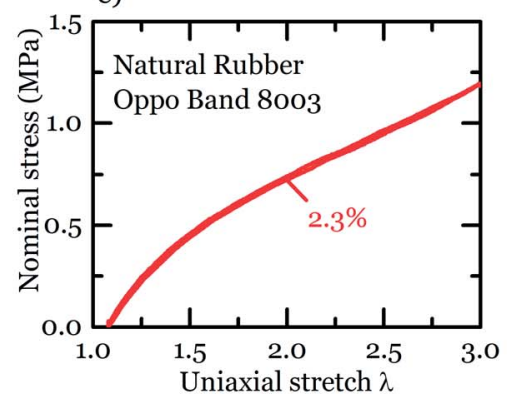

c)
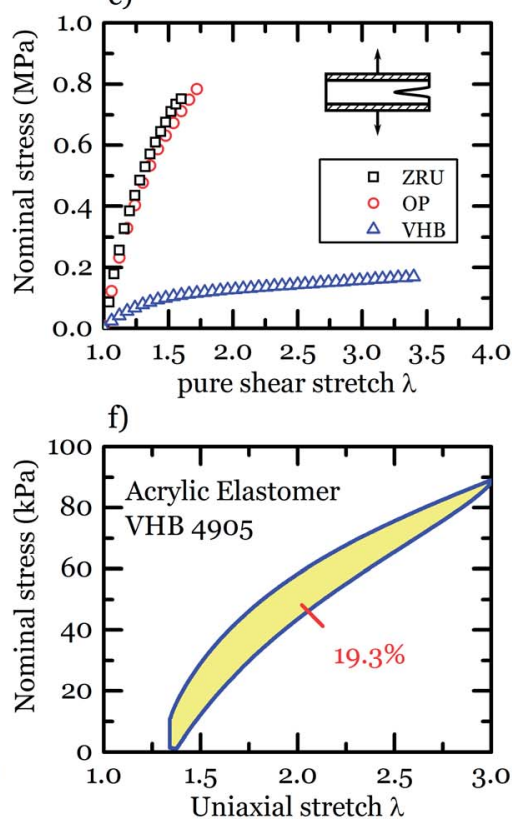

Fig. 2 Material properties of elastomers. (a) The dielectric strength of ZRU, OP and VHB increases with biaxial stretch. Natural rubber provides up to three times larger dielectric strength compared to VHB. (b) ZRU and OP are much stiffer than VHB. The experimental stress-stretch relation at $100 \% / s$ strain rate (symbols) is well described by the Gent model (solid lines). (c) To determine the durability of soft materials, precut samples are stretched at a strain rate of $100 \% / s$ and the stretch at rupture is used to obtain the fracture energy. (d-f) Hysteresis behaviour is depicted after the $100^{\text {th }}$ uniaxial loading-unloading cycle. Here the distinctive viscoelasticity of VHB leads to a comparably large hysteresis loss.

Table 1 Material properties of VHBTM 4910, ZruElast ${ }^{\mathrm{TM}}$ A1040 and Oppo Band ${ }^{T M} 8003$. The strain rate at which values were obtained is specified in \%/s where appropriate. The Gent parameter determines the maximum stretch and the strengthening exponent describes the stretch dependence of the dielectric strength

\begin{tabular}{|c|c|c|c|}
\hline Property & $\begin{array}{l}\text { VHB }^{\text {TM }} \\
4910\end{array}$ & $\begin{array}{l}\text { ZruElast }^{\mathrm{TM}} \\
\text { A1040 }\end{array}$ & $\begin{array}{l}\text { Oppo Band } \\
8003\end{array}$ \\
\hline $\begin{array}{l}\text { Shear modulus }(100 \% / \mathrm{s}) \\
\mu[\mathrm{kPa}]\end{array}$ & 52 & 917 & 466 \\
\hline Gent parameter $(100 \% / \mathrm{s}) J_{\lim }$ & 114 & 44 & 43 \\
\hline $\begin{array}{l}\text { Unstretched dielectric } \\
\text { strength } E_{\mathrm{B}}\left[\mathrm{MV} \mathrm{m}^{-1}\right]\end{array}$ & 69 & 120 & 97 \\
\hline Strengthening exponent $R$ & 0.54 & 0.70 & 0.99 \\
\hline $\begin{array}{l}\text { Relative dielectric } \\
\text { permittivity }(1 \mathrm{kHz}) \varepsilon_{\mathrm{r}}\end{array}$ & 4.2 & 3.4 & 2.8 \\
\hline Loss tangent $(1 \mathrm{kHz}) \tan \delta$ & $2.5 \times 10^{-2}$ & $5.6 \times 10^{-3}$ & $2.0 \times 10^{-3}$ \\
\hline Hysteresis loss $(5 \% / \mathrm{s})$ & $19.3 \%$ & $7.0 \%$ & $2.3 \%$ \\
\hline $\begin{array}{l}\text { Fracture energy }(100 \% / \mathrm{s}) \\
\Gamma\left[\mathrm{kJ} \mathrm{m}^{-2}\right]\end{array}$ & 3.92 & 6.15 & 7.21 \\
\hline
\end{tabular}

slightly lower conversion capability of ZRU due to lower dielectric strength and maximum stretch.

\section{Material assessment in soft generators}

We converted mechanical energy to electrical energy using a particular experimental setup (Fig. 4). We approximately achieved an idealized electromechanical cycle (Fig. 4a) by using a circuit (Fig. 4b) and an air chamber covered with a dielectric elastomer membrane (Fig. 4c). This circuit consists of a low voltage $\left(\Phi_{\mathrm{L}}\right)$ reservoir of charge and a high voltage $\left(\Phi_{\mathrm{H}}\right)$ reservoir of charge, represented by two capacitors of large capacitances $C_{\text {in }}$ and $C_{\text {out }}{ }^{\mathbf{8}, 30,31}$ The two diodes ensure that the electric current only flows from the input to the output reservoir. Several different designs could be employed ${ }^{32}$ and for an unambiguous measurement of the energy balance a simple design is implemented, such that all useful electric energy is stored in two reservoirs before and after a generation cycle. The two reservoirs, $C_{\text {in }}$ and $C_{\text {out }}$, are first charged to low and high voltage respectively. Beginning from an uncharged state for the dielectric elastomer generator, charges will flow from $C_{\text {in }}$ to the generator while stretching. The voltage across $C_{\text {in }}$ and the generator will eventually equalize, and charging continues at constant voltage until the maximum mechanical stretch is attained. Here, we ensure that the charges on $C_{\text {in }}$ and $C_{\text {out }}$ are much larger than the maximum charge on the dielectric elastomer generator, such that the voltages on $C_{\text {in }}$ and $C_{\text {out }}$ are only slightly affected by transfer of charges to/from the generator. When the pressure reduces, the dielectric elastomer membrane reduces its area and increases its thickness. Consequently the membrane boosts the voltage until it matches that of the output capacitor, and begins to pump charges into $C_{\text {out }}$. This process of constant voltage charge pump by mechanical relaxation continues until the membrane is fully relaxed. The cycle is repeated. The corresponding yield of the electrical energy by the soft generator per cycle is:

$$
W_{\text {ele }}=\Phi_{\mathrm{H}} \Delta Q_{\text {out }}-\Phi_{\mathrm{L}} \Delta Q_{\text {in }}
$$



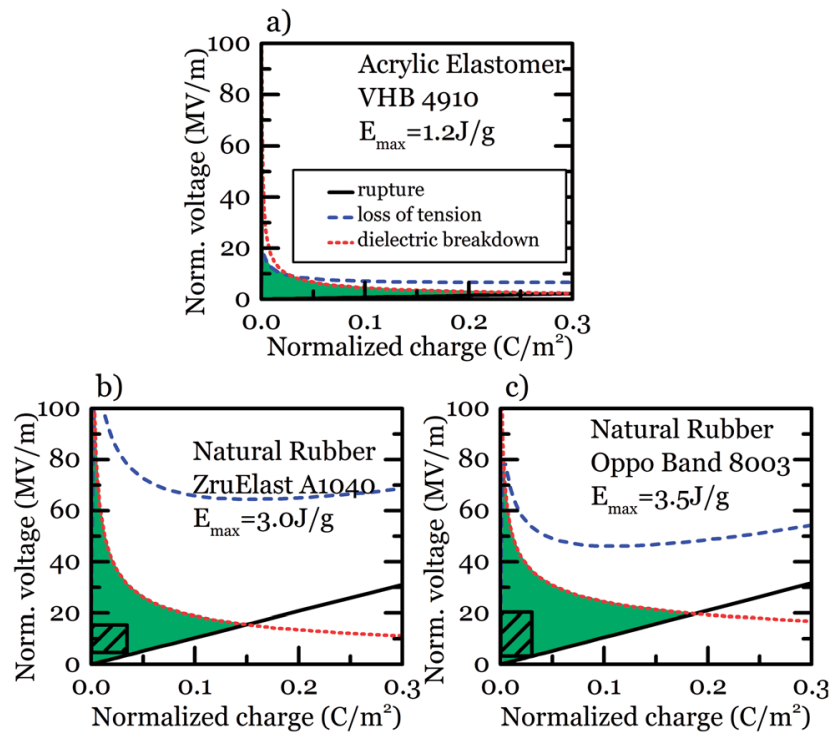

Fig. 3 Aptitude of materials for soft generators. In a soft generator both natural rubbers, Oppo Band 8003 (OP) and ZruElast A1040 (ZRU), outperform acrylic elastomer VHB4910 (VHB) in terms of maximum energy that can be converted $\left(E_{\max }\right.$ in $\left.(a-c)\right)$. This is due to the significantly larger dielectric strength and mechanical stiffness of natural rubber over acrylic elastomer ( $b$ and $c$ ). $E_{\max }$ is determined by an area enclosed by material limits of mechanical rupture, loss of tension and dielectric breakdown, plotted on work-conjugate planes of voltagecharge. An energy conversion cycle of a lossless system, traced along the limits gives $E_{\max }$. The hatched rectangle in ( $\mathrm{b}$ and $\mathrm{c}$ ) depicts the actual experimental energy conversion cycle reported in this work.

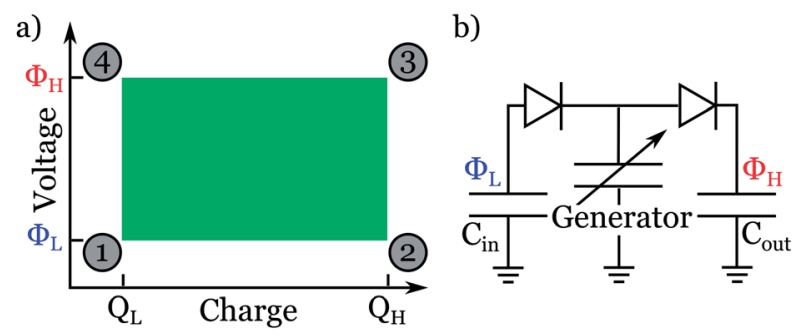

c)

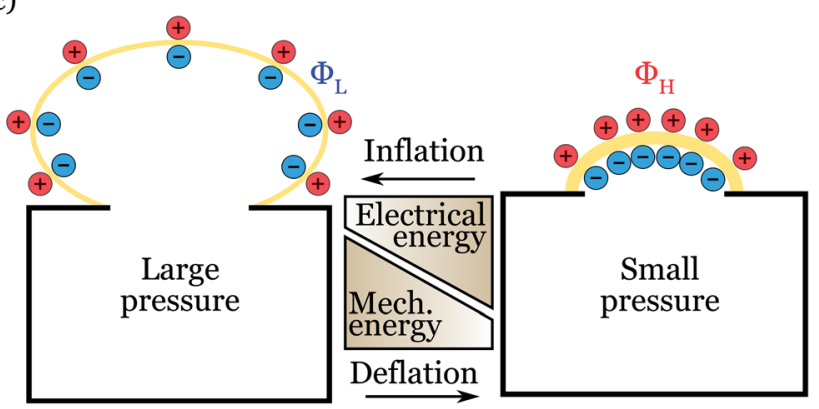

Fig. 4 Experimental design of a soft generator based on charge reservoirs of low and high potential. Balloon inflation is used to provide mechanical energy. (a) A Carnot-inspired cycle on the voltage-charge plane is selected for this experiment. (b) The soft generator operates between reservoir capacitors at low $\left(\Phi_{\mathrm{L}}\right)$ and high $\left(\Phi_{\mathrm{H}}\right)$ potential. Diodes direct charges on the generator to be pumped from low to high potential. (c) Pressurized air is used to inflate the elastomer membrane (yellow) to a stretched state. Subsequent deflation relaxes the membrane, and converts mechanical energy into electrical energy. where $\Delta Q_{\text {in }}$ is the net charge transferred from $C_{\text {in }}$ to the membrane at voltage $\Phi_{\mathrm{L}}$, and $\Delta Q_{\text {out }}$ is the net charge transferred from the membrane to $C_{\text {out }}$ at voltage $\Phi_{\mathrm{H}}$.

We deform a flat membrane into a balloon by pressurizing a chamber (Fig. 4c). This technique allows the membrane to undergo equal-biaxial stretching at areas around its apex, which enlarges as the membrane inflates. The mechanical work done on the membrane per cycle of operation is:

$$
W_{\text {mech }}=\int p \mathrm{~d} V
$$

here $p$ is the applied pressure, and $V$ is the volume of the balloon. $W_{\text {mech }}$ is represented by the area bounded by the $p-V$ curve.

The maximum electrical energy yield $W_{\text {ele }}$ is proportional to the volume of the membrane, the dimensions of the membrane are of no importance. Larger thickness linearly increases applicable voltages, while the charge on the membrane remains constant as the increase of voltage is compensated by a decreasing capacity. Increasing the area of the membrane does not affect the voltages, but linearly increases the amount of charge stored on the membrane. A similar argumentation also leads to the conclusion that $W_{\text {mech }}$ is proportional to the volume and thus all energy related quantities can be normalized by the volume of the elastomer membrane and due to incompressibility also by the mass.

By monitoring the voltage $\Phi$, the pressure $p$ and the balloon volume $V$ of the soft generator we can hence track the mechanical and electrical energy flow through the soft generator and determine the specific electrical energy and specific average power.

This method was previously used to assess the aptitude of VHB4910 resulting in a specific electrical energy output per cycle of $102 \mathrm{~mJ} \mathrm{~g}^{-1}$ and specific average power of $17 \mathrm{~mW} \mathrm{~g}^{-1} .^{8}$

\section{Energy harvesting using ZruElast ${ }^{\mathrm{TM}}$ A1040}

For a lossless membrane under equal-biaxial stretch, energy conversion scales to the fourth power of the stretch - a membrane stretched to two times its original dimensions boosts electrical energy to 16 times the amount of input energy when relaxed. This highly effective manner of energy conversion can be adopted in a diverse range of energy harvesting applications. ${ }^{33-36}$

Fig. 5a shows the generator capacitance change over two orders of magnitude due to the inflation of the membrane during the experiment (represented by open triangles in Fig. 5a). This is in agreement with numerical simulations (red line in Fig. 5a), adapted from Li et $a l^{37}$ Fig. 5b tracks the histories of experimentally determined quantities pressure $(p)$, volume $(V)$, voltage $(\Phi)$ on the membrane and net charge $\left(Q_{\text {net }}\right)$ transferred to the membrane, during the 6th cycle using the setup introduced in Fig. 4. Many materials experience a stressstrain hysteresis upon cyclic loading which fades to a small value after few cycles. The evolution of the hysteresis loss is presented in ESI, Fig. S4 $\uparrow$ and shows that from the $6^{\text {th }}$ cycle onward all analyzed materials already experience low hysteresis 
a)

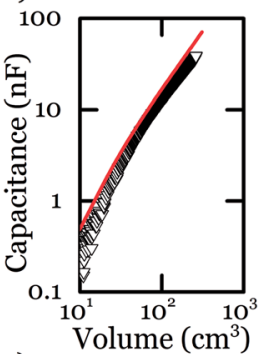

c)

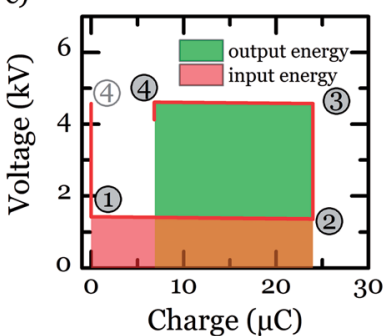

b)

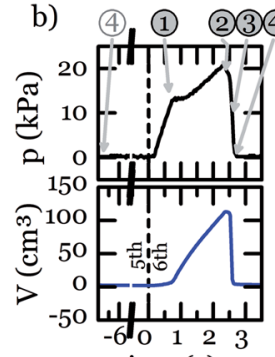

ime $(s)$

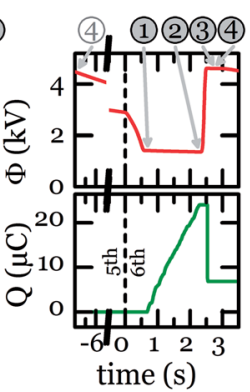

time (s)

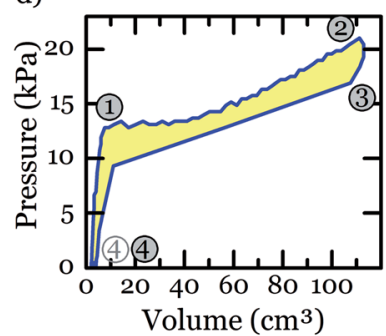

Fig. 5 Experimental generation of electric energy using ZruElast A1040 in a soft generator. (a) The electrical capacitance of the elastomer membrane changes by two orders of magnitude due to inflation. The red line depicts theoretical calculations for capacitance change, showing good agreement with experiment. (b) The recorded pressure, volume, voltage and charge as functions of time during the $6^{\text {th }}$ generation cycle. Encircled numbers mark states of the soft generator corresponding to those in Fig. 4a. (c) Measured generator cycle depicted in the electrical work-conjugate plane. This cycle is not closed due to charge leakage. Charge lost due to leakage results in the gap between the initial charge and the charge at the final point of the cycle. The electrical energy input (148 $\mathrm{mJ} \mathrm{g}^{-1}$, red area), and the output (358 $\mathrm{mJ} \mathrm{g}^{-1}$, green area) total in net generated energy of 210 $\mathrm{mJ} \mathrm{g}^{-1}$. (d) The path depicted in the mechanical work-conjugate plane enclosing an area of $1.4 \mathrm{~J} \mathrm{~g}^{-1}$ resulting in a 'mechanical-to-electrical' energy conversion efficiency of $14.9 \%$.

loss which is comparable to the long term values shown in Fig. 2d-f.

The $5^{\text {th }}$ cycle ends approximately 7 seconds before the $6^{\text {th }}$ cycle starts with the generator being at a state of high voltage and minimum charge. During this period, leakage currents lead to a slow voltage drop. At $t=0 \mathrm{~s}$ the generator cycle starts by inflating the membrane, increasing its capacitance while keeping the charge constant until the voltage matches that of the input reservoir at point $1(t=0.67 \mathrm{~s})$. Upon further inflation charge is transferred from the input reservoir to the membrane which reaches its maximum volume and capacitance (pt. 2) at $t=2.29 \mathrm{~s}$.

In the following deflation stage the charge is again confined to the membrane and the voltage increases, reaching the level of the output reservoir at point $3(t=2.53 \mathrm{~s})$. Subsequent deflation results in transferring charges from the membrane to the output reservoir, until the minimum volume is reached (pt. 4) at $(t=2.55 \mathrm{~s})$. In this experimental cycle, the specific electrical energy generated was $210 \mathrm{~mJ} \mathrm{~g}^{-1}$, the mechanical energy consumed was $1.4 \mathrm{~J} \mathrm{~g}^{-1}$, resulting in a 'mechanical-to-electrical' conversion efficiency of $14.9 \%$ and a specific average power of $82.4 \mathrm{~mW} \mathrm{~g}^{-1}$. As some charge leaked through the membrane $(6.4 \mu \mathrm{C})$ the cycle is not closed since more charge was

transferred from the input reservoir $\left(Q_{\text {in }}=23.6 \mu \mathrm{C}\right)$ to the membrane than transferred from the membrane to the output reservoir $\left(Q_{\text {in }}=17.2 \mu \mathrm{C}\right)$.

\section{Energy harvesting using Oppo Band ${ }^{\mathrm{TM}} 8003$}

The typical conversion cycle depicted in Fig. 3 was also used to assess the aptitude of OP for soft generators and the results are shown in Fig. 6 . On the last leg of the $5^{\text {th }}$ cycle $(t<0 \mathrm{~s}$, point 4 of $5^{\text {th }}$ cycle), the voltage at the membrane drops due to charge leakage. The $6^{\text {th }}$ cycle commences upon inflation of the membrane, resulting in a sharp voltage drop that matches the voltage at $C_{\text {in }}$, given by pt. 1 at $t=0.34 \mathrm{~s}$. Charges transfer from $C_{\text {in }}$ to the membrane at constant voltage up to a prescribed maximum stretch, given by pt. 2 at $t=1.73 \mathrm{~s}$. At this point, the membrane deflates, resulting in an open-circuit voltage boost. The voltage of the membrane matches the voltage of the output reservoir at pt. 3 at $t=1.84 \mathrm{~s}$. After that, charges are transferred to $C_{\text {out }}$ at constant voltage as the membrane continues to deflate until it is flat, given by pt. 4 at time $t=1.85 \mathrm{~s}$. Fig. $4 \mathrm{c}$ gives the measured voltage and charge states on the voltage-charge plane. This plot is compared with the ideal cycle in Fig. 4a. It was experimentally observed that the charge transferred from $C_{\text {in }}$ to the membrane $\left(\Delta Q_{\text {in }}=21.2 \mu \mathrm{C}\right)$ is not fully transferred to $C_{\text {out }}\left(\Delta Q_{\text {out }}=15.7 \mu \mathrm{C}\right)$. This represents a leaked charge of 5.5 $\mu \mathrm{C}$. From (2), the electrical energy yield is $369 \mathrm{~mJ} \mathrm{~g}^{-1}$. With the cycle time of $1.85 \mathrm{~s}$, the specific average power is $200 \mathrm{~mW} \mathrm{~g}^{-1}$.
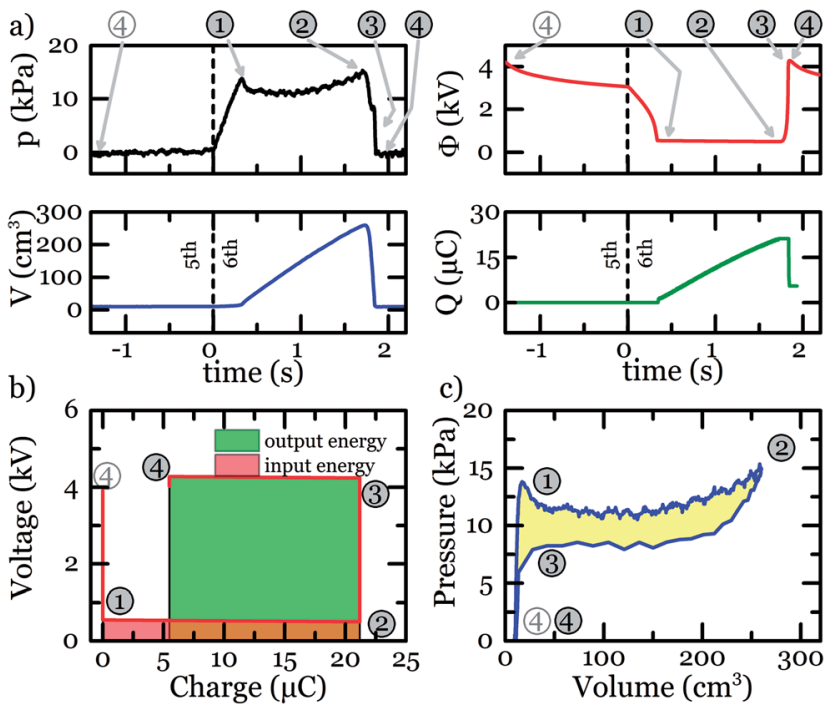

Fig. 6 Experimental generation of electric energy using OppoBand 8003 in a soft generator. (a) Histories of mechanical variables of pressure $p$ and volume $V$, and electrical variables, of voltage $\Phi$ and net charge $Q$. The measurements were made during the $6^{\text {th }}$ cycle. (b) The path of the soft generators state in the electrical work-conjugate plane. The shaded areas indicate electrical input (red) and output (green) energy. The specific electrical energy generated in this cycle is computed as $369 \mathrm{~mJ} \mathrm{~g}^{-1}$, at an average power of $200 \mathrm{~mW} \mathrm{~g}^{-1}$. (c) Measured generator cycle plotted on the mechanical work-conjugate plane. The enclosed area represents the mechanical energy supplied at $5.1 \mathrm{~J} \mathrm{~g}^{-1}$. This gives a 'mechanical-to-electrical' energy conversion efficiency of $7.2 \%$. 
From (1), the mechanical energy is $5.1 \mathrm{~J} \mathrm{~g}^{-1}$, giving a 'mechanical-to-electrical' conversion efficiency of $7.2 \%$.

These are among the highest experimental values of specific average power and energy reported in the literature for soft generators. Using a different setup with equal biaxial deformation the highest reported value for a soft generator using VHB is $280 \mathrm{~mW} \mathrm{~g}^{-1}$ and $560 \mathrm{~mJ} \mathrm{~g}^{-1}$. $^{38}$

\section{Implications on wave energy harvesting}

Existing designs for ocean wave energy harvesting ${ }^{2}$ currently work at high levelized costs of electricity (LCOE). ${ }^{3}$ The LCOE is calculated by accounting for all costs within the expected system lifetime, divided by the energy output of the system. Pelamis is the world's first wave energy converter (WEC) that supplies power to electrical grids. ${ }^{39}$ It consists of long, rigid steel pipes with joints that flex with ocean waves. To convert sufficient energy for power grids, each Pelamis module is about 200 $\mathrm{m}$ long, and operates at an LCOE of 26.5-61.7 ct kW ${ }^{-1} \mathrm{~h}^{-1} .^{40}$ Similar to the Pelamis, the Oyster, ${ }^{41}$ Drakoo, Archimedes wave swing, ${ }^{2}$ Anaconda, ${ }^{42}$ point source buoy converter ${ }^{2}$ and the terminator Salter Duck ${ }^{\mathbf{4}}$ devices simply channel power from waves to drive rotary or linear generators. These generators, known as power take-off systems,${ }^{44}$ contribute significantly to the cost of the wave energy converters. ${ }^{45}$ The cost of steel and concrete is also significant due to costly material production and maintenance in the harsh ocean environment.

Here we identify natural rubber as a material for soft energy generators that allow for ocean wave energy harvesting at a potentially low LCOE in the range of 5-11 ct kW $\mathrm{kW}^{-1} \mathrm{~h}^{-1}$, significantly lower than currently available technology. The very high energy density, ${ }^{36,46}$ the lack of moving parts ${ }^{\mathbf{1 6}}$ and the inherent impedance matching ${ }^{47}$ are unique benefits of soft wave energy generators.

The LCOE for soft WECs are estimated based on an analysis of the Pelamis wave energy converter. ${ }^{\mathbf{4 0 , 4 5}}$ The LCOE of Pelamis are modified to match material cost, estimated lifetime and estimated savings on maintenance when using soft materials for the structure and adjusted for the different specific power. Details are available online in ESI, Fig. S2. $\dagger$

Natural rubber is harvested from plants, has a low carbon footprint ${ }^{48}$ and low material cost. ${ }^{49}$ Pará rubber trees (Hevea brasiliensis) exist in abundance Southeast Asia. They are a hardy species, with a single mature tree capable of producing a continuous supply of latex for up to 25 years. ${ }^{50}$ For example, Thailand, Indonesia and Malaysia, the world's top three producers of natural rubber, produced 7.4 million metric tons of rubber in $2011 .^{49}$ Natural rubber production is sustainable due to low soil nutrient depletion and the long productive life of rubber trees.

Natural rubber-based generators are very promising due to the low cost of material production and high energy conversion potential. We demonstrated that soft, natural rubber generators have high specific power resulting in systems that are lightweight and low cost. It is observed that the fracture energy is twice as high for rubber compared to VHB at a strain rate of $100 \% / \mathrm{s}$. It has been shown in previous works that the fracture energy of amorphous polymers is correlated with their fatigue life against cyclic loading. ${ }^{51}$ We may hence conclude that both rubbers are more durable against cyclic operation than VHB.

The demonstrated specific power of $200 \mathrm{~mW} \mathrm{~g}^{-1}$, at a fraction of the costs of current technologies may allow large-scale production of economical, portable and durable mechanical energy harvesting systems. To replace a large power plant (1 GW) the amount of rubber needed is $10^{5}$ tons assuming a conservative power density on the order of $10 \mathrm{~kW} \mathrm{t}^{-1}$. This is only $1 \%$ of the annual rubber production.

The key challenges of implementing mechanical energy harvesting systems lie in system size and cost. ${ }^{16}$ This challenge is particularly important in ocean wave energy harvesting,

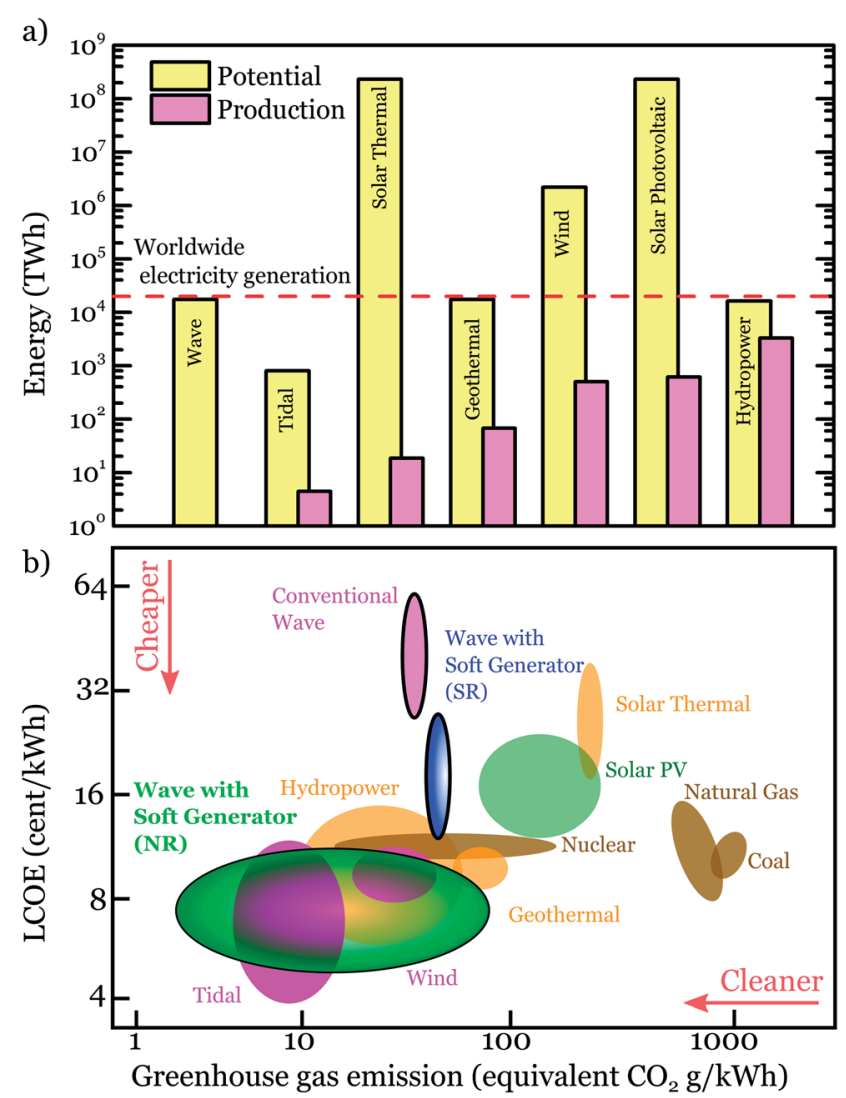

Fig. 7 Natural rubber-based soft generators as a clean and economical method to convert mechanical energy of ocean waves to electricity. (a) The full potential of major sources of renewable energy (yellow bars) and their actual contribution to electricity production (pink bars). The full potential of wave energy is on par with the worldwide electricity generation, and is comparable with hydropower and geothermal sources; but its annual production is negligible. Wave energy therefore presents a huge untapped source of clean energy. (b) Production cost (LCOE) versus carbon footprint (greenhouse gas emission) of various energy sources (both renewable and fossil fuel). Harvesting energy from ocean waves with existing technologies (conventional wave) emits twenty times less greenhouse gas than natural gas and coal, but its levelized cost of electricity (LCOE) is more than four times higher. High LCOE prevents large scale exploitation of wave energy. Soft generators based on silicone rubber (in blue) already halve the level of LCOE compared to conventional techniques. On the other hand, natural rubber-based soft generators (in green) can significantly reduce LCOE and greenhouse gas emission. 
where wave energy converters must be of low cost and be able to generate energy in isolation. Comparably small wave energy converters with high energy density may enable the harvesting of wave energy close to conurbations with heavy sea traffic leaving the sea channels obstruction-free avoiding long transmission paths.

An alternative lower cost soft material-based wave energy converter ${ }^{16}$ using natural rubber operates at $28 \%$ (5-11 ct $\mathrm{kW}^{-1}$ $\mathrm{h}^{-1}$ ) of the LCOE of Pelamis. This estimate is based on a detailed analysis of Pelamis ${ }^{\mathbf{4 5 , 5 2 - 5 4}}$ which is adapted to the different material and maintenance cost, structure, and power density of a soft wave energy converter. The details of this estimation are found in ESI. $\uparrow$ The estimation assumes achieving a real-world power density in ocean environments of only $1 \%$ ( $2 \mathrm{~kW}$ per ton) of the maximum power density achieved under laboratory conditions (200 kW per ton). The reason behind this conventional assumption is that a large scale wave energy converter will certainly include additional parts adding to its weight, while operating for a very long lifetime demands for operation under safe conditions reducing the electrical power output. The resulting power density of $2 \mathrm{~kW}$ per ton are comparable with the power density reported from wave tank tests of a similar device using silicone rubber (1.1 kW per ton). ${ }^{16}$

The significance of this result is emphasized by the fact that today no existing technology is capable to tap into the huge resource of ocean wave energy at competitive prices. Fig. 7a compares the potential energy supply and the actual production of different resources to the amount of electric energy generated in 2009 (20 $043 \mathrm{TW}$ h). ${ }^{3}$ Although marine waves provide a huge renewable resource, with a total potential at the same level as the yearly energy needs of the world, ${ }^{55}$ it is largely untapped.

Furthermore, the simplicity of production and low maintenance of natural rubber based structures cause greenhouse gas emissions as low as $1.5 \mathrm{~g} \mathrm{CO}_{2}$ eq. per $\mathrm{kW}$ per h as compared to Pelamis' $28 \mathrm{~g} \mathrm{CO}_{2}$ eq. per kW per h. ${ }^{56}$ Fig. 7b compares LCOE and greenhouse gas emissions of different technologies for generation of electricity. Details of the method for estimating the LCOE and a referenced version of Fig. 6 are found online in ESI, Fig. S1-3. $\dagger$

\section{Conclusion}

The discovery of natural rubber as an electromechanical generator creates the possibility of developing mechanical harvesting systems that are sustainable and low in cost. Its high fracture energy promises high durability and lifetime, the outstanding combination of mechanical and electrical properties are responsible for high specific energy and power in soft generators and all this comes in one package in well-known natural rubber at a low material price.

The technology can be used to harvest ocean energy to feed into the energy grid as well as harvesting energy from ambient environment to power portable devices and remote sensors. Recent advances in material design using nanoscale fillers enhance permittivity as well as dielectric strength ${ }^{57,58}$ which could lead to optimized rubber based materials and improve the performance of soft generators, opening up more and more possibilities for soft energy harvesting.

\section{Acknowledgements}

The authors are grateful to Dr Zrunek for the kind supply of natural rubbers. The authors from the Johannes Kepler University Linz acknowledge funding from the ERC through the Advanced Grant "Soft-Map" and from the Austrian Science Fund under the DACH-Project FWFI00986000. The authors at Harvard acknowledge funding from the NSF MRSEC (DMR0820484). Rainer Kaltseis acknowledges funding through a Marshall Plan Scholarship from the Austrian Marshall Plan Foundation. Choon Chiang Foo acknowledges support from A*STAR Graduate Scholarship (Post-doctoral Fellowship). Soo Jin Adrian Koh acknowledges funding support from Ministry of Education (Singapore), for Academic Research Funding (Tier 1), project no.: R302000013133.

\section{Notes and references}

1 G. Hagerman, G. Scott and P. Jacobson, Mapping and Assessment of the United States Ocean Wave Energy Resource, Electrical Power Research Institute, 2011, Technical report 1024637, available at http:// www.eere.energy.gov/water/pdfs/ mappingandassessment.pdf.

2 B. Czech and P. Bauer, Wave Energy Converter Concepts: Design Challenges and Classification, IEEE Ind. Electron. Mag., 2012, 6, 4-16.

3 S. Chu and A. Majumdar, Opportunities and challenges for a sustainable energy future, Nature, 2012, 488, 294-303.

$4 \mathrm{~J}$. Mullaly, The Laying of the Cable, Or the Ocean Telegraph, D. Appleton and Company, 1858.

$5 \mathrm{~J}$. R. Chaplin, et al. Development of the ANACONDA allrubber WEC, in Proc. 7th EWTEC, 2007.

6 R. Pelrine, et al. Dielectric elastomers: Generator mode fundamentals and applications, Proc. SPIE, 2001, 4329, 148.

7 S. J. A. Koh, Maximum Energy that can be Harvested from a Dielectric Elastomer Generator, in MRS Symp. Z, 2009, vol. $1218 \mathrm{E}$, p. 1218.

8 R. Kaltseis, et al. Method for measuring energy generation and efficiency of dielectric elastomer generators, Appl. Phys. Lett., 2011, 99, 162904.

9 T. G. McKay, B. M. O'Brien, E. P. Calius and I. A. Anderson, Soft generators using dielectric elastomers, Appl. Phys. Lett., 2011, 98, 142903.

10 J. Maas and C. Graf, Dielectric elastomers for hydro power harvesting, Smart Mater. Struct., 2012, 21, 064006.

$11 \mathrm{~T}$. Vu Cong, C. Jean-Mistral and A. Sylvestre, Electrets substituting external bias voltage in dielectric elastomer generators: application to human motion, Smart Mater. Struct., 2013, 22, 025012.

12 T. Li, S. Qu and W. Yang, Energy harvesting of dielectric elastomer generators concerning inhomogeneous fields and viscoelastic deformation, J. Appl. Phys., 2012, 112, 034119. 
13 Y. Liu, et al. Analysis and manufacture of an energy harvester based on a Mooney-Rivlin-type dielectric elastomer, EPL, 2010, 90, 36004.

14 C. Jean-Mistral, S. Basrour and J.-J. Chaillout, Dielectric polymer: scavenging energy from human motion, Proc. SPIE, 2008, 6927, 692716.

15 I. A. Anderson, T. A. Gisby, T. G. McKay, B. M. O'Brien and E. P. Calius, Multi-functional dielectric elastomer artificial muscles for soft and smart machines, J. Appl. Phys., 2012, 112, 041101.

16 P. Jean, et al. Standing wave tube electro active polymer wave energy converter, Proc. SPIE, 2012, 8340, 83400C.

17 F. Carpi, S. Bauer and D. De Rossi, Materials science. Stretching dielectric elastomer performance, Science, 2010, 330, 1759-1761.

18 J. Biggs, et al. Electroactive Polymers: Developments of and Perspectives for Dielectric Elastomers, Angew. Chem., Int. Ed. Engl., 2013, 52, 9409-9421.

19 P. Brochu and Q. Pei, Advances in Dielectric Elastomers for Actuators and Artificial Muscles, Macromol. Rapid Commun., 2010, 31, 10-36.

20 M. Pharr, J.-Y. Sun and Z. Suo, Rupture of a highly stretchable acrylic dielectric elastomer, J. Appl. Phys., 2012, 111, 104114.

21 Zrunek Gummiwaren GmbH, Zrunek Rubber Technology, 2013, at http://www.zrunek.at/uk/ukhome.html.

22 Oppo Medical Inc, Oppo Medical | Orthopedic | Oppo Band, at http://www.oppomedical.com/product/detail.asp? serno $=260$.

23 3M, Industrial Adhesives \& Tapes, at http:// solutions.3m.com/wps/portal/3M/en_US/Adhesives/Tapes/ Products/ /All-3M-Products/Industry-and-Professionals/3MTape-and-3M-Adhesives/Double-Sided-Bonding-Tapes/3MVHB-Tape Ntt $=4910 \& \mathrm{rt}=\mathrm{s}$.

24 C. Chiang Foo, et al. Performance of dissipative dielectric elastomer generators, J. Appl. Phys., 2012, 111, 094107.

25 A. Tröls, et al. Stretch dependence of the electrical breakdown strength and dielectric constant of dielectric elastomers, Smart Mater. Struct., 2013, 22, 104012.

26 S. J. A. Koh, C. Keplinger, T. Li, S. Bauer and Z. Suo, Dielectric Elastomer Generators: How Much Energy Can Be Converted?, IEEE ASME Trans. Mechatron., 2011, 16, 33-41.

27 A. N. A. Gent, New Constitutive Relation for Rubber, Rubber Chem. Technol., 1996, 69, 59-61.

28 F. Bueche, Molecular basis for the mullins effect, J. Appl. Polym. Sci., 1960, 4, 107-114.

29 A. Dorfmann and R. W. Ogden, A constitutive model for the Mullins effect with permanent set in particle-reinforced rubber, Int. J. Solids Struct., 2004, 41, 1855-1878.

30 S. J. A. Koh, X. Zhao and Z. Suo, Maximal energy that can be converted by a dielectric elastomer generator, Appl. Phys. Lett., 2009, 94, 1-13.

31 H. U. Fuchs, A surrealistic tale of electricity, Am. J. Phys., 1986, 54, 907-908.

32 C. Graf, J. Maas, B. M. Ag \& D. Schapeler, Electromechanical Energy Conversion using Dielectric Elastomer Generators, in 12th Int. Conf. New Actuators - ACTUATOR 2010, 2010, pp. 834-837.

33 A. Crossland, P. Wyllie and L. Ran, Mechanical to electrical energy conversion in a hybrid liquid-solid dielectric electrostatic generator, J. Appl. Phys., 2009, 106, 044108.

34 T. Sterken, P. Fiorini, K. Baert, R. Puers \& G. Borghs, An electret-based electrostatic $\mu$-Generator, in ISSSAM, 2003, pp. 1291-1294.

35 R. Tashiro, et al. Development of an electrostatic generator that harnesses the motion of a living body (use of a resonant phenomenon), JSME Int. J., Ser. A, 2000, 43, 916922.

36 R. D. Kornbluh, et al. From boots to buoys: promises and challenges of dielectric elastomer energy harvesting, Proc. SPIE, 2011, 7976, 797605.

$37 \mathrm{~T}$. Li, et al. Giant voltage-induced deformation in dielectric elastomers near the verge of snap-through instability, $J$. Mech. Phys. Solids, 2013, 61, 611-628.

38 J. Huang, S. Shian, Z. Suo and D. R. Clarke, Maximizing the Energy Density of Dielectric Elastomer Generators Using Equi-Biaxial Loading, Adv. Funct. Mater., 2013, 23, 50565061.

39 J. Scruggs and P. Jacob, Harvesting ocean wave energy, Science, 2009, 323, 1176-1178.

40 M. O'Connor, T. Lewis and G. Dalton, Techno-economic performance of the Pelamis P1 and Wavestar at different ratings and various locations in Europe, Renewable Energy, 2013, 50, 889-900.

41 A. Babarit, et al. Numerical benchmarking study of a selection of wave energy converters, Renewable Energy, 2012, 41, 44-63.

42 F. J. M. Farley, R. C. T. Rainey and J. R. Chaplin, Rubber tubes in the sea, Philos. Trans. R. Soc., A, 2012, 370, 381-402.

43 S. H. Salter, Wave Power, Nature, 1974, 249, 720.

44 B. Drew, A. R. Plummer and M. N. Sahinkaya, A review of wave energy converter technology, Proc. Inst. Mech. Eng., Part A, 2009, 223, 887-902.

45 M. Previsic, R. Bedard, H. George and O. Siddiqui, System Level Design, Performance and Costs for San Francisco California Pelamis Offshore WavePower Plant, Electrical Power Research Institute, 2006, E2I EPRI Global-006A-SF, available at http://oceanenergy.epri.com/attachments/wave/ reports/006_San_Francisco_Pelamis_Conceptual_Design_1211-04.pdf.

46 S. P. Beeby, et al. A micro electromagnetic generator for vibration energy harvesting, J. Micromech. Microeng., 2007, 17, 1257-1265.

$47 \mathrm{H}$. Prahlad et al. Polymer Power: Dielectric Elastomers and Their Applications in Distributed Actuation and Power Generation, in ISSS, 2005, pp. 100-107.

48 W. Jawjit, C. Kroeze and S. Rattanapan, Greenhouse gas emissions from rubber industry in Thailand, J. Cleaner Prod., 2010, 18, 403-411.

49 Food and Agriculture Organisation of the United Nations (FAOSTAT), Production of Unprocessed Crops, 2012, at http://faostat3.fao.org/faostat-gateway/go/to/download/T/TP/E. 
50 M. R. Sethuraj \& N. M. Mathew Natural rubber: Biology, cultivation and technology, Elsevier Science, 1992, vol. 622.

51 A. Griffith, The phenomena of rupture and flow in solids, Philos. Trans. R. Soc., A, 1921, 221, 163-198.

52 C. McGowin, et al. Renewable Energy Technical Assessment Guide-TAG-RE, 2006, Electrical Power Research Institute, 2007, Final report 1012722, available at http://www.epri.com/abstracts/Pages/ProductAbstract.aspx? ProductId $=000000000001012722$.

53 M. Previsic, O. Siddiqui and R. Bedard, Economic Assessment Methodology for Offshore Wave Power Plant, Electrical Power Research Institute, 2004, E2I EPRI WP-US-002 Rev 4, available at http:/oceanenergy.epri.com/attachments/wave/reports/ 002_Rev_4_Econ_Methodology_RB_12-18-04.pdf.
54 C. Anderson, Pelamis WEC - Main Body Structural Desgin and Materials Selection, (DTI New and Renewable Energy Programme, 2003).

55 K. Gunn and C. Stock-Williams, Quantifying the global wave power resource, Renewable Energy, 2012, 44, 296-304.

56 R. P. M. Parker, G. P. Harrison and J. P. Chick, Energy and carbon audit of an offshore wave energy converter, Proc. Inst. Mech. Eng., Part A, 2007, 221, 1119-1130.

57 T. Tanaka, Dielectric nanocomposites with insulating properties, IEEE Trans. Dielectr. Electr. Insul., 2005, 12, 914928.

58 E. Tuncer, et al. Enhancement of dielectric strength in nanocomposites, Nanotechnology, 2007, 18, 325704. 